\title{
Raphaël Confiant (dir.), Nouvelles des mondes créoles
}

\section{Carminella Biondi}

\section{Q OpenEdition}

\section{Journals}

\section{Edizione digitale}

URL: http://journals.openedition.org/studifrancesi/1658

DOI: 10.4000/studifrancesi. 1658

ISSN: 2421-5856

\section{Editore}

Rosenberg \& Sellier

\section{Edizione cartacea}

Data di pubblicazione: 1 novembre 2014

Paginazione: 648

ISSN: 0039-2944

\section{Notizia bibliografica digitale}

Carminella Biondi, «Raphaël Confiant (dir.), Nouvelles des mondes créoles », Studi Francesi [Online], 174 (LVIII | III) | 2014, online dal 01 novembre 2014, consultato il 18 septembre 2020. URL : http:// journals.openedition.org/studifrancesi/1658; DOI : https://doi.org/10.4000/studifrancesi.1658

\section{Questo documento è stato generato automaticamente il 18 settembre 2020.}

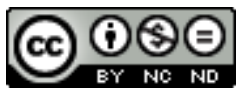

Studi Francesi è distribuita con Licenza Creative Commons Attribuzione - Non commerciale - Non opere derivate 4.0 Internazionale. 


\title{
Raphaël Confiant (dir.), Nouvelles des mondes créoles
}

\author{
Carminella Biondi
}

\section{NOTIZIA}

RAPHAËL CONFIANT (dir.), Nouvelles des mondes créoles, Paris, Écriture, 2013, pp. 254.

1 Questa preziosa antologia raccoglie undici novelle inedite, provenenti in larga misura dalle Antille francofone (Guadalupa, Guyana, Haiti e Martinica), nello specifico: una ciascuna la Guadalupa e la Guyana, due Haiti, cinque la Martinica; le due restanti provengono rispettivamente da Réunion e Maurice. Dieci sono un prodotto insulare, mentre una, quella guyanese, proviene dalla punta Nord Ovest del continente sudamericano, normalmente inserita nell'area caraibica, anche perché la Guyana fa parte, insieme a Martinica e Guadalupa, dei territori francesi d'oltremare. Il volume è aperto da una breve, ma limpida introduzione, in cui lo scrittore e studioso martinicano Raphaël Confiant, ricostruisce la nascita delle scritture "creole", con cui si indicano non, o non solo, gli scritti in lingua creola, ma quelli prodotti in paesi di colonizzazione, le cui lingue si sono formate grazie ad apporti linguistici multipli (anche quando la lingua utilizzata resta quella del colonizzatore): le Antille, in cui sono arrivati i neri strappati alla terra d'Africa, che hanno vissuto l'esperienza prima della schiavitù poi dell'emarginazione, e le isole dell'Oceano Indiano, in cui alla schiavitù e all'emarginazione nera si è aggiunta quella indiana. La sintetica ricostruzione delle storie e dei percorsi letterari che hanno caratterizzato questi paesi si avvia alla conclusione con un'analisi più specifica della scrittura in lingua creola e di alcuni autori che l'hanno utilizzata nelle loro opere, del ruolo che ha avuto il movimento della "Créolité", nato in Martinica verso la metà degli anni '80, ad opera dello stesso Confiant, di Bernabé e di Chamoiseau, e si conclude infine con una breve presentazione delle nuove voci creole raccolte in questo volume (alcune a dire il vero già molto note come vedremo). Uno spazio non trascurabile, anche se ancora minoritario, è riservato alle scrittrici: quattro su undici. Tutti i testi sono in lingua francese, con inserzioni a 
volte tradotte (nel testo o in nota) a volte no di creolo, quando si tratti di esprimere l'intraducibile nella lingua europea o di meglio connotare il radicamento della storia nel suo contesto. Sono tutti racconti molto godibili, in cui, quasi sempre, la realtà e i fantasmi dell'invisibile concorrono in egual misura alla costruzione del racconto e provocano quella sensazione di muoversi in una zona altra, quasi fiabesca, anche se talvolta la fiaba è molto cruda e lascia intravvedere, in particolare per quanto concerne Haiti, la brutalità del potere e la precarietà di vite allo sbando. Mentre la scrittura al femminile riesce molto bene a coniugare rivendicazione (magari implicita nel racconto di soprusi) e sogno. Questo connubio fra realismo, magia, con l'aggiunta di una buona dose di ironia, vale in larga misura per tutti i racconti nati in area caraibica, mentre quelli dell'oceano indiano sono ancorati ad un maggiore realismo, anche se in tutti la lingua si carica di forti sfumature poetiche. Il fatto nuovo, in queste novelle, è che ormai il periodo della colonizzazione non è più al centro della storia, anche se resta sullo sfondo come componente ineludibile.

2 Di seguito, mi limiterò ad elencare i contributi, lasciando al lettore il piacere della scoperta, anche se non so resistere alla tentazione di invitare ad un confronto fra la novella di Raphaël Confiant, intitolata Diablesse (pp. 73-85), che racconta in versione martinicana il mito delle sirene, e L'homme qui aimait les Néréides di Marguerite Yourcenar, che, come il precedente, narra la storia di una fascinazione mortifera, tratta da una leggenda "orientale". Anche se con il suo sberleffo finale, Confiant ci riporta con i piedi per terra e ci conferma che siamo in un altro mondo. Dopo aver denunciato la povertà dei miti moderni, creati in larga misura dal cinema e dalla televisione, esclama: «Nostalgie: ô Diablesses du temps mythologique créole, comme je vous regrette!» (p. 85).

Ecco le novelle riunite in questa antologia (corredata anche da un'ampia bibliografia), che ha il grande merito di metterci in contatto, grazie alla scelta della forma breve, con uno specimen abbastanza rappresentativo dell'ultima scrittura creola. Le novelle sono precedute da una breve biografia degli scrittori: Dominique BATRAVILLE (Haiti), L'apologie de Maudira (pp. 37-58); Mérine cÉco (Martinica), Le fossoyeur des langues (pp. 57-71); Charles-Henri FARGE (Martinica), Nyotimori (pp. 87-98); Dany LAFERRIÈrE (Haiti), Truman Capote au Park Hôtel (pp. 101-126); Dominique LANCASTRE (Guadalupa), Ka moun ke di? (racconto realistico di violenza sulle donne da parte del marito, pp. 127-143); Karen LAURÉOTE (Martinica), Sa Majesté Ernès (pp. 145-162); Catherine LE PELletIER (Guyana), Tempo Duo (storia tragica di soprusi in Brasile e di fughe in Guyana, pp. 163-187); JeanFrançois SAMLong (Réunion), Un cercueil en plein ciel (pp. 189-203); Anique SYLVESTRE (Martinica), Comment la jeune Pilibo sauva le jardin extraordinaire (pp. 205-236); Khal TORABULLY (Maurice), L'eau n'efface pas tout (pp. 237-251). 